"This is an Accepted Manuscript of a chapter published in the book: Innovation and Technology enhancing Mathematics Education. Perspectives in the Digital Era. Springer, ISBN: 978-3-31961488-5, available online: https://link.springer.com/book/10.1007/978-3-319-61488-5 DOI:

https://doi.org/10.1007/978-3-319-61488-5 2"

\title{
From acorns to oak trees: charting innovation within technology in mathematics education
}

\author{
Susana Carreira, Alison Clark-Wilson, Eleonora Faggiano and Antonella Montone
}

\section{Abstract}

Technology has created an expectation in all phases of education that requires us to understand how we can harness its potential for improving the depth and quality of mathematical learning. It is highly unlikely that there is a universal recipe or formula for how technology should be used that would satisfy every context or culture, but there have been recurring trends in the process of designing and implementing such innovative environments. By considering the papers included in proceedings of the past International Conferences on Technology in Mathematics Teaching (ICTMT), this chapter aims to highlight how a few key innovations have been seeded and taken root within this community. We begin by describing the ways in which innovation has been presented at ICTMT conferences with a view to exploring this from the perspectives of technology designers, researchers and teachers/lecturers from all phases of education. Given the extensive literature on this topic, it is not feasible to carry out a comprehensive survey of the complete literature base, however it is anticipated that the analysis of key ICTMT papers will be sufficient to present an informative and insightful picture and highlight some important knowledge and experience that has been elicited and disseminated.

\section{Introduction}

The first Conference on Technology in Mathematics Teaching (ICTMT) took place in Birmingham UK, in 1993, under the stewardship of Professor Bert Waits of the University of Colombus, Ohio in an attempt to develop an international conference series in the spirit of the US-based Conference for Technology in Collegiate Mathematics, which Bert and his colleague Frank Demanna had first chaired in 1988. The late 1980s and early 1990s was a period of great innovation for technology within mathematics education, which saw the introduction of the first handheld graphing calculators, the development of computer algebra languages such as Derive, Mathematica and MatLab, programming languages such as LOGO and the emergence of dynamic geometry software (DGS) such as Cabri-Géomètre and The Geometer's Sketchpad, which was greatly assisted by the design of the computer mouse.

In this first conference, contributions were sought in the form of peer-refereed papers that would be offered as presentations, shorter papers offered as workshops and thematic topics for a series of 
symposiums. In each case, the contributors were asked to submit their proposals according to one of the three conference themes:

1. The mathematical content of teaching and learning environments.

2. Technology as a resource for the teacher.

3. Hands-on interaction between learners and technology.

In addition, the contributors were asked to classify their contributions according to the level of educational interest (Primary teachers, Secondary teachers, Teacher-Educators and Lecturers in Higher Education) and to highlight whether their paper reported aspects of Research, Development and Teaching.

The subtlety of the decision by the original scientific committee to welcome contributions beyond traditional papers that reported empirical research was an important one - and one that has shaped the content and ethos of all of the subsequent ICTMT conferences since 1993. By welcoming papers that reported aspects of Development and Teaching, it opened the ICTMT conference to embrace innovation as participants sought to share their designs of technological tools/environments and/or educational courses, teaching materials and reports on teaching/learning outputs as 'work in progress'. Consequently, although the academic rigour, systematic evaluation and reporting of some of these early innovations was as yet undetermined, it gave the opportunity for the conference community to share new developments at an earlier stage.

It is in this context that we have chosen to examine the way in which important technological innovations within the field of mathematics education have been seeded in the form of acorns, taken root and, in some cases, grown into mighty oak trees. We did this by means of a historical review of the ICTMT proceedings (see Appendix 1) in which we foregrounded the plenary talks so as to identify some seminal themes and, following this, we scrutinised the peer-reviewed paper submissions $^{1}$ and workshop session topics to chart how these themes evolved over the subsequent years.

Drawing on the perspectives that the plenary speakers have proposed throughout the ICTMT conferences and in line with findings from significant texts in the field (e.g. Hoyles and Lagrange, 2009; Hoyles and Noss, 2003; Kaput, 1999; Shaffer and Kaput, 1999; Moreno-Armella, Hegedus and Kaput, 2008; Laborde and Sträßer, 2010) we have identified the following themes that have proved to be significant with respect to the path of innovation in the field. These are:

1. The concept of a mathematical 'figure' and the new action of 'dragging'.

2. Multiple representations in mathematics (2-Dimensional and 3-Dimensional)

This chapter is structured as follows. After a short explanation of how we interpret the idea of 'innovation', we take each of these themes in turn and, drawing on key contributions to the ICTMT conference series, highlight how the ideas have evolved in the field.

In our final section, we build on these themes to describe some of the innovative technologies that have been showcased at ICTMT conferences that have particularly impacted on how we interact with, and communicate about, mathematics. For example, touch screen technologies, video, ebooks, online communities and competitions - all set against a back drop of increasingly ubiquitous access.

\footnotetext{
${ }^{1}$ For one of the early conferences (ICTMT2, Edinburgh 1995) we did not have access to the complete peerreviewed papers, only the accepted abstracts.
} 


\section{Defining innovation from the ICTMT conference series perspective}

Any historical review should take account of the context in which the reported phenomena occurred and, in beginning a historical review on technological innovation in mathematics, we have to cast our minds back to the typical classroom or research environment of the early 1990s. In these pre-internet days, most technology was 'stand-alone', although locally networked computer 'suites' were emerging. The data projector (and interactive whiteboard) were still in development, meaning that the whole class display of a computer screen was still a challenge, although some classrooms achieved this using television screens. The transfer of files was a physical one, involving computer discs and the computer mouse was becoming a 'standard' peripheral device for the newer computers.

As a conference series on technology in mathematics teaching, one might imagine that there is a clear and widespread understanding of what is meant by 'technology' amongst the community of conference participants. Unsurprisingly, the word technology is one of the most frequent words to appear in the written proceedings; indeed, the range of meanings for the word is vast and it includes:

- Technology that is the platform through which the digital media is accessed and or made visual - this has traditionally been called the 'hardware'. For example, Personal Computer, Laptop computer, iPad, mobile phone, graphing calculator, data logger.

- Technology that provides the means through which teachers and learners access some mathematics content - traditionally the software, or more recently applets and widgets! Examples include classes of software such as: dynamic graphing software (Autograph, Mouseplotter); computer algebra software (Mathematica, MathCad, Wolfram Alpha, Derive); dynamic geometry software (DGS) (Cabri-Géomètre, The Geometer's Sketchpad,) and more recently software packages that combine mathematical representations and functionality (TI-Nspire, GeoGebra, TinkerPlots).

- Technology that communicates mathematical content as either a one-way (video, informative web-pages) or two-way (intelligent support).

- Technology that combines some or all of the above to create portals (Census at School), 'elearning environments' or support 'blended learning'.

These seem to form a natural timeline as the technology often appears first, followed by classroom experimentation and then, in time, the design of more substantial courses and assessment approaches that bring the technology to more classrooms. However, this could be a slow process as, in the early days of technology use in education, researchers tended to adopt positivist approaches that used formal scientific methods that did not take full account of the diversity of teachers, students, classrooms and cultures, and variables involved. For example, by using a control group methodology and identical pre- and post-testing protocols for each group, particular effects on the learning outcomes like the role of the teacher, previous knowledge of the students or issues related to the underlying technological and pedagogical environment were often overlooked. This led quite quickly to the conclusion that many mathematical technologies changed the nature of the mathematical knowledge that was being taught - and so required different methodological approaches (Artigue, 2002). This resulted in the growth of the use of design-based research approaches (diSessa and Cobb, 2004) that integrate the processes of the design of the technology alongside systematic evaluation in partnership with stakeholders and, as a result, can fast-track the latter stage by adopting simultaneous design innovation. 


\subsection{Innovation in the design and evaluation of technological tools}

The ICTMT conference series has always attracted participants whose primary interest has been in the design of technological environments for the learning and teaching of mathematics. Often, the conferences have been used as major 'design showcases' at which new features and functionalities are shared and conference participants have often been the first to experience such innovations. For example, Cabri-Géomètre (ICTMT1, Birmingham, 1993), Autograph (ICTMT6, Volos, 2003), Mathematica (ICTMT7, Bristol, 2005), Casyopée (ICTMT8, Hradec Kralové, 2007) and CabriElem (ICTMT10, Portsmouth, 2011), TouchCounts (ICTMT11, Bari, 2013).

There have always been tensions within the education community concerning the relationships between all those involved in technology design. Many technological products emerge from the academic research community but, as they prove their efficacy and develop their user base, it often becomes necessary to partner with or create commercial enterprises in order to market and distribute the resource more widely. Alternatively, academics and teachers collaborate with existing technology companies to develop and evaluate products with a commercial aim. In both scenarios, the respective aims of educational researchers, teacher educators, technology designers, teachers and students are of high importance as each partner seeks to maintain its principles and values. For example, the technology designer might seek to implement a new functionality because it is technically possible, whereas a teacher or researcher might be more concerned with how such functionality might influence or change the mathematical knowledge or its associated pedagogy.

The collaborations between the different people involved in the design and evaluation of educational technology for mathematics has led to a number of theoretical ideas that have supported an understanding of the ways in which teachers and learners begin to make sense of and use such innovations. For example, the important theoretical constructs of instrumentation/instrumentalisation (see Verillon and Rabardel, 1995 and, within mathematics education, Guin and Trouche, 1999), situated abstraction (Noss and Hoyles, 1996), structuring features of classroom practice (Ruthven and Hennessy, 2002) and semiotic mediation (BartoliniBussi and Mariotti, 2008).

De Freitas, Ferrara and Ferrari bring in a new theoretical perspective to analyze and conceive the relation between the user and the tool: "assemblage theory furnishes innovative ways of thinking about individual human bodies and how they come together with technology". On the other hand, it brings to light an issue that did not appear overtly in our revision of ICTMT papers: technology and its relation to games, including interactive digital games that make extensive use of sensorial elements. "This research makes use of technology that is related to the game console Nintendo Wii because of the potential that it offers in terms of playing games through proprioception and kinaesthesia. The devices under consideration are the remote controllers (also called Wii Remotes, or Wiimotes) and the Balance Board of the Wii. The remote controllers are devices with which users can control and play games where real movement simulations are produced. The Wii balance board is usually used for games that depend on balance and body perception in space".

\subsection{Innovation in the design and evaluation of classroom tasks}

In reviewing the proceedings, it is not always possible to distinguish aspects of the design and evaluation of the technological tool from those concerning the design and evaluation of the associated mathematical task(s). Consequently, we interpret this aspect of innovation as that which is predominantly reported by authors who have taken technological tools that have been created by others within which to design classroom tasks that use the inherent software 
functionality. For example, a high school teacher proposing a range of mathematical tasks for secondary students using the Microsoft Excel programme (see the paper by Broman, in Fraunhalz, 1997).

\section{Some key innovations in mathematics education}

\subsection{The concept of a mathematical 'figure' and the new action of 'dragging'}

The advent of the computer graphic image that could be constructed and acted upon using the computer mouse, graphics tablet and pen and more recently figure or stylus driven touch screens was a major technological development that took place in the late 1980s and early 1990s. Within mathematics education, this led to the development of dynamic geometry software (DGS) (The Geometry Inventor, Cabri-Géomètre, The Geometer's Sketchpad, Cinderella, GeoGebra), a key feature of which was the functionality to use a set of geometric construction features to define 2-D (and also 3-D) 'figures', which could be transformed by selecting constituent parts of the figure and 'dragging' with the computer mouse. This was a revolutionary new way of experiencing a mathematical environment that extended the idea of a mathematical 'drawing' - a mathematical sketch that, although not necessarily accurate, incorporated mathematical properties. In her seminal plenary during the first ICTMT, Colette Laborde offered the following scenario to indicate how a 'Cabri figure' could be constructed in different ways to enable different points to be free to move on the circle (see Fig.1).

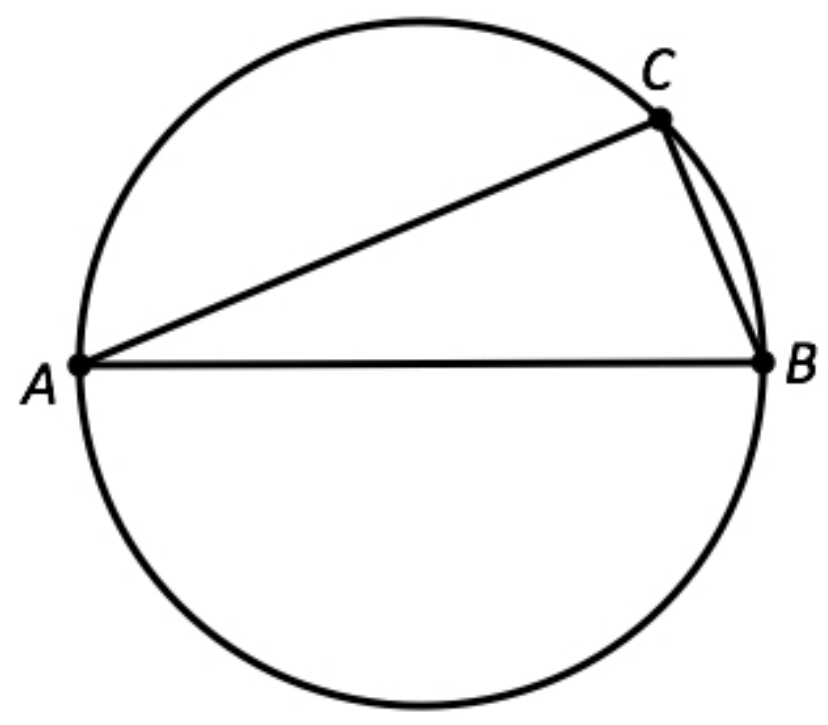

Figure 1 The right triangle (Laborde in Jaworksi, 1993. p.44)

As software developed over time, so the 'drawing' of a function such as $y=x^{2}$ might include key features such as set of perpendicular axes, a curved graph (the shape of a parabola) and with a minimum at $(0,0)$. In dynamic technological environments, such drawings can become figures whereby classes of mathematical objects (geometric shapes, geometric scenarios, algebraic functions etc.) can be constructed and interacted upon by 'dragging'. 
In this section, we explore 'figures and dragging' from the perspective of the initial design and evaluation of the associated technologies before then considering the innovative design and evaluation of classroom tasks within such environments.

\subsubsection{Figures and dragging from the perspective of the innovative design/evaluation of tools}

In her plenary address at the first ICTMT conference, Colette Laborde, who was a member of the Cabri-Géomètre design team, shared this innovative new software with the conference participants and in doing so, offered some important definitions that were seminal in their influence of later research and practice (Laborde in Jaworski, 1993). In the paper that accompanied her plenary, Colette made the important distinction between the idea of a 'drawing', which is 'imperfect' in that 'the lines have a width, the straight lines are not really straight' (ibid. p.41) to the 'idealized' drawing of the mathematician, in which such imperfections are ignored through to the consideration that, in a computerised environment, 'to what extent the imperfections of a drawing are considered a noise by the users?'. Within the context of dynamic geometry, Colette then introduced the idea of a (Cabri-Géomètre) 'Figure' as a particular type of mathematical drawing which, due to its dynamic construction based on a set of (Euclidean) geometric rules, retained its mathematical properties when free objects were varied by dragging. The open nature of the construction and transformation functionality enabled a multitude of geometric figures to be constructed, from the simple case of a dynamic isosceles triangle to more complex geometric scenarios that model known and unexplored problems from traditional geometry.

In the evolutionary path of dynamic geometry tools, the dragging functionality is a major developmental milestone that was evident from the early design and, with time has become an essential feature of most subsequent mathematical digital technologies.

Some subsidiary developmental milestones include:

- The translation of traditional geometry tools to their digital equivalences.

- A move from plane geometry to the design of 3-D geometric environments.

- The overlaying/underlying of a Cartesian plane - leading to the functionality to drag objects within multi-representational mathematical environments.

- The use of parameters and sliders to support mathematical modelling.

- The use of video/images as a context for modelling mathematics in a dynamic way.

- The use of macros (Cabri) or tools (Sketchpad, GeoGebra), which enable procedures to be captured in a process that has a strong resonance with computer programming.

The combination of dragging functionality alongside the digital representations of Euclidean geometry tools on the computer screen (ruler, compass, straight-edge and protractor) may be considered to be at the heart of the development of DGS. These capabilities have provided a new way of interacting with geometrical objects and their properties, namely by enhancing visualization, understanding, and a motivation for the analysis and discovery of geometrical properties. The designers enthusiastically pointed to opportunities of making the teaching and learning of mathematics more lively and relevant, more fun, appealing and stimulating, particularly by giving learners 'visual hooks to hang on' (Butler, in Triandafillidis \& Hatzikiriakou, 2003).

Moreover and simultaneously, from the viewpoint of teachers and researchers, there is a clear perception that DGS is of great potential to emphasise conceptual understanding in geometry. For example, giving the perspective of a classroom teacher, Clark-Jeavons (in Borovcnik \& 
Kautschlitsch, 2002) makes an a priori synthesis of a variety of new approaches centred on conceptual understanding, not just related to the production of dynamic and interactive representations (the pointer as an extension of the hand through the mouse interface) but also profiting from complementary features. The ways in which DGS is effective in developing geometrical understanding concerns 'visual creation and interpretation', 'support in deductive proof', 'means for making and testing conjectures', 'black box activities', 'visual proof', and 'reinterpretation of the static geometry".

The early versions of dynamic geometry environments sought to simulate and emulate the purity of Euclidean geometry and its structure, which translated into highly robust mathematical constructions being created on the computer. The robustness of those constructions, such as polygons with certain characteristics or other figures where points, lines or segments were dependant on certain primitive objects, was markedly one of the capabilities that mathematicians, researchers and mathematics educators considered to be both innovative and important. But for teachers, purism was soon balanced with the possibility of creating and using macros that allow users (for example, younger students) to perform rigorous constructions (e.g. to create an equilateral triangle) without having to go through all of the construction steps each and every time. As an example Don Hoyle, in his account of his educational experience with school students learning about families of quadrilaterals and their classification (in Maull \& Sharp, 1999), mentioned that students and also teachers found some of the 'more pure' versions of DGS more difficult to use. Therefore it favoured the availability of plugged-in features that allow pre-designed constructions as opposed to the classical Euclidean way of doing them. 'The first version of CabriGeometre was very purist, in that the only tools you had were, as in pure Greek Geometry, a ruler and a compass' (p.1). Alongside this, there was an acceptance that it is not always desirable or necessary for students to create figures from scratch. Tasks are as valid when students are required to work on figures already constructed by acting upon them or changing them in some way, as a way of revealing important properties and features of those figures.

One significant paper on the evolution of DGS and its design principles was given by Elschenbroich (in Borovcnik \& Kautschlitsch, 2002) who emphasised that the main affordance of such environments was the opportunity to investigate invariants, functional dependencies and loci. $\mathrm{He}$ asserted that the drag mode and the revealing of loci are two important functionalities that extended those of (digital) construction using of compass, straightedge, ruler and protractor. The resulting digital figures are classes of drawings holding the same properties and relationships and Elschenbroich argued that the purpose of teaching and learning geometry should be directed to investigate what changes and what remains invariant. Moreover, as measures can be made dynamically, it became possible to calculate with such dynamic measures and even to create new constructions using those measures. Therefore, the new dragging action was extended to coordinates, measurements and equations. And the figures could also go beyond the user's constructions as it became possible to produce them under the form of loci. Dragging a point could be interpreted as leaving a visible trace and thus generating a new object - a locus. Such loci remained available as new objects that could lead to new mathematical investigations. The meaning of dragging thus became much broader than it was before.

Another storyline concerns the evolution of technological tools from plane geometry to geometry in three dimensions, which became visible at the ICTMT conferences through the development of 3-D DGS software. This innovation transported the dragging functionality that had been developed for 2-D DGS and made it possible for points, lines, vectors and surfaces to be manipulated in 3-D space. 
Alongside this, the teaching and learning of coordinate geometry, non-Euclidean geometry and other versions of algebraic approaches to geometry gained new perspectives by appropriating the dynamic nature of the changing of drawings in a figure and the corresponding change in the equations and/or parameters involved in coordinates and Cartesian equations. For instance, Adrian Oldknow (in Borovcnik \& Kautschlitsch, 2002) commented on the advances and developments of DGS by stressing the start of a link between geometric and algebraic representations: 'The current versions of Cabri and GSP both provide the means to use the results of measurements and calculations based on them to define the position of points in a Cartesian coordinate system. Thus they can be used as algebraic tools where a graph of a function can be created as the locus of a point whose $y$-coordinate is a given function of its $x$-coordinate' (p. 84).

One prominent innovation concerns the combination of and connections between geometric objects and algebraic objects/symbols in ways that capitalise on the dynamic properties of many of these software products alongside the nature of the underlying mathematical constructions. Roanes-Lorenzo (in Borovcnik \& Kautschlitsch, 2002), in collaboration with other Spanish researchers, described the creation of a combined package, called Lugares, that made it possible to link dynamic geometry and algebra. The author claimed that DGS and CAS packages had attained high levels of development but they had evolved independently. The aim was therefore to develop a software package that provided the equations of any drawn configurations - in particular those of parameter-dependent geometrical constructions. 'In Lugares, numerical approaches to dynamic geometry can be complemented with the symbolic capabilities of CAS, letting a step forward to draw loci and find their equations' (ibid, p. 361).

Indeed, this combination of geometry and algebraic equations in coordinate systems was promptly felt as an important innovation for the work with figures that depended on the variation of parameters. For example, innovative ways of dealing with conics (see Broman in Borovcnik \& Kautschlitsch, 2002) or investigations on functions and their graphs in relation to the change of areas or distances began to emerge and be discussed as legitimate mathematical tasks, sometimes in tune with a problem-solving or a modelling approach to mathematics (See LopezReal in Olivero \& Sutherland, 2005 and Miller \& Ehmann in Triandafillidis \& Hatzikiriakou, 2003).

We note that by the mid 2000s, the community's knowledge and understanding of dragging (by then an essential affordance of DGS) was consolidating, and the action of dragging was becoming more and more intrinsic and even 'natural' within DGS environments. This in turn was generating ever more specific and more diverse results in terms of the kinds of representations offered and combined within mathematical tasks.

Although the development of software that enabled the progression from 2-D to 3-D contexts is an important benchmark in the process of innovation, the ability to generate loci and work with them in concrete ways, namely by dragging them, should be acknowledged as a significant step forward. The example given by Miller and Ehmann, in which the locus of the intersection points of the altitudes of triangles with constant height is described, is illustrative of this and, as the authors argue, it 'puts across a first impression of the transition from an elementary geometric problem to a question in calculus' (Triandafillidis \& Hatzikiriakou, 2003, p. 315).

\subsubsection{Figures and dragging from the perspective of the innovative design and evaluation of classroom tasks}

The ICTMT proceedings tell an interesting story with respect to the development of innovative classroom tasks that utilised the ideas of dynamic geometric figures that could be constructed and 
interacted upon by dragging. During ICTMT1, which featured the seminal plenary by Colette Laborde, there was only one other paper (Little in Jaworski, 1993) that made reference to how dynamic geometry software (Cabri-Géomètre) might influence the future design of classroom tasks. Little makes specific reference to the importance of the distinction between a figure and a drawing when clarifying geometric concepts. Little writes, 'In cabri, we construct a 'figure', then by dragging vertices we see different 'drawings' which exemplify the figure. This distinction can be used to illustrate and clarify the distinction between, for example, 'square' and 'squareness'.' In his paper, Little suggests such tasks might become legitimate in a technology enhanced school geometry curriculum in England.

The strong attention given by researchers, teachers and lecturers to the dragging action was reflected not only in the exploratory, inquiring and investigative nature of the tasks supported by DGS but also within the theorizing of different modes of dragging and of the role of dragging in mathematical activity involving the construction and manipulation of figures on the screen.

In her paper presented at ICTMT 4, Federica Olivero (in Maull \& Sharp, 1999) reported outcomes of a study with 15-year-old students in which a theoretical model of 'dragging modalities' was proposed. The study was described as follows: 'Pupils were requested to produce conjectures in open geometric situations, to validate and, finally, to prove them. These activities took place within the microworld Cabri-Géomètre. (...) We found out that different dragging modalities are crucial for producing a shift from conjecturing to proving: these modalities can be analysed as the perceptive counterpart of the cognitive processes students use.' (ibid. p. 567).

This particular study showed that the students' use of dragging in Cabri changes with respect to the control that the students have of the situation. It also showed that dragging acts as a mediator of the students' activity on proof. The essential argument is that dragging supports the production of conjectures given that exploring figures by moving and manipulating them allows the users to discover invariant properties of those figures. Besides, the possibility of dragging has another major function, that of generating useful feedback in the phase of discovering properties and furthermore supporting the finding of a proof as an 'explanation' of the property or the conjecture made.

This mediating role of the tool and especially the dragging action has continued to be investigated and still remains important in the research about the mathematical thinking afforded by DGS in tasks that clearly highlight the dragging function in deduction, explanation and proof.

It is worth pointing out that the views of teachers and researchers did not always seem to coincide with regard to evaluating the affordance of dragging. While teachers tended to look at the dragging as handy to help students overcoming difficulties in concept acquisition, researchers were theorising the dragging action and conceptualising the subtleties of this feature in students' activity from exploration into proof. For example, in the work presented by Kordaki, Balomenou, and Pintelas (In Triandafillidis\& Hatzikiriakou, 2003) students were asked to construct several triangles and then to transform them into other equivalent triangles. The difficulty of the concept of equivalent triangles (conservation of the area) was the motivation for the study. The authors claimed the innovative character of this DGS approach to the conservation of the area. The main result of the teaching approach was that students 'viewed the concept of conservation of the area of a triangle as an alteration of its position on the computer screen as well as an alteration of its figure' (ibid. p. 181) and 'using the drag mode ... students had the opportunity to observe a large number of equivalent triangles', 'thereby forming a dynamic view of this concept' (ibid. p. 181). Thus the emphasis in the dragging action was related to the possibility of observing a large number 
of cases. In short, the power of dragging was absorbed by many teachers, in the tasks they have produced for their students, as opportunities to visualise and to make sense of a concept or property, which would not be feasible to produce on paper.

\subsection{The concept of multiple representations}

Since the late 1980's a growing appreciation of the importance of multiple representations has been considered an essential component in the process of learning mathematics. The learning or doing of mathematics implies not only manipulating mathematical symbols, but the interpretation and coordination of mathematical relationships and situations, using specialised language, symbols, images and graphs. It also involves the clarification of problems, deduction of consequences and development of appropriate tools (National Research Council, 1989).

Moreover, in the USA, the National Council of Teachers of Mathematics (NCTM, 1989) published 'Curriculum and Evaluation Standards for School Mathematics', in which multiple representations are considered as one of the fundamental aspects of the curriculum that should be emphasised during the teaching and learning of mathematics. According to the document's authors, students who have flexible tools for solving problems are able to interpret the same problem or the same mathematical concepts through its multiple representations.

Other researchers at this stage and thereafter in the 1990's were devoting much attention to the role of representations and to the importance of translations between multiple representations in students' learning and understanding (of numbers, algebra, functions, etc.) and also to the multirepresentational capacity of many developing software (e.g. Fey, 1989; Schwarz, Dreyfus \& Bruckheimer, 1990; Borba \& Confrey, 1996).

Some of the contributions at ICTMT corroborate this trend. Gomes Ferreira (in Fraunhalz, 1997) suggests that the incorporation of multiple representations in mathematics teaching can empower and help students to develop their understanding of mathematical relationships and concepts and improve their perceptions of mathematics by emphasising the linkages between graphical, tabular, symbolic and verbal descriptions of mathematical relationships and mathematical problem situations.

This view is concurred by Ozgun-Koca, who says that multiple representations can be defined as 'external mathematical embodiments of ideas and concepts to provide the same information in more than one form' (Ozgun-Koca, 1998, p.3). For example a linear function can be viewed as a set of ordered pairs, a correspondence in a table or a mapping, a graph, or an algebraic expression. Examples of external multiple representations include verbal representations (written words), graphical representations (Cartesian graphs), algebraic or symbolic representations (equations expressing the relationship between two or more quantities), pictorial representations (diagrams or drawings) and tabular representations (table of values) among a host of others (see Fig.2). 


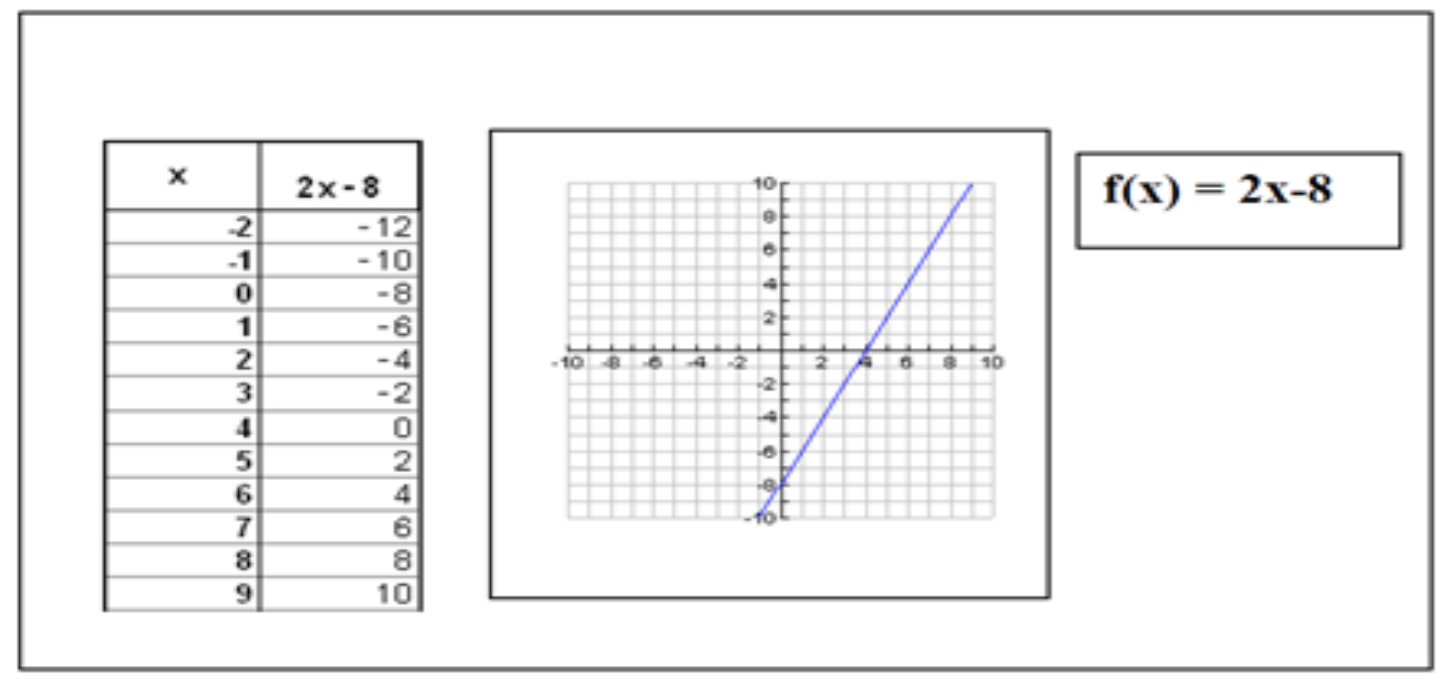

Figure 2 Multiple representations of the linear function, $f(x)=2 x-8$ (Adu-Gyamfi, 1993, p.11)

Innovation in technology design has led to the development of digital environments that enable multiple linked representations to be acted upon such that the relationships between mathematical representations can be made more visible. Depending upon the design of the associated mathematical tasks, students and teachers can focus their activity on establishing and justifying the underlying mathematical links and connections.

\subsubsection{Multiple representation from the perspective of the innovative design/evaluation of tools}

The analysis of the ICTMT proceedings shows that one of the most influential technological tools to use multiple representational functionalities in mathematics has been Texas Instruments' TI-92 graphing calculator. Since the early 1980s developments and applications through different experiences in school mathematics education have been reported that exploit its multiple representations. Aspetsberger (In Maull \& Sharp, 1999) presented the outcomes of classroom work with students aged 16, who were mainly interested in art and languages and not in natural sciences. The author's goals were to use the TI-92 to make traditional mathematical content more visual and accessible for the students. For example, referring to teaching calculus and problems associated with the tangent, the author says that 'especially for optimization problems the different representation modes of the TI-92 (table, graph, expression) were very helpful for illustration. The students learned how to detect minima and maxima in tables, graphs and to verify them by means of calculus. For curve analysis the permanent availability of graphs was very illustrative'. And, referring to the experiences, she also says 'One of the main advantages of the TI-92 are [sic] the different forms of representation (tables, graphs, expressions) which are always available on the TI-92 and can lead to a better understanding of mathematical concepts. The students have the possibility to choose a representation form they like most e.g. for solving problems, for illustration or to get an overview in a certain situation. It is remarkable, that most students choose tables or graphs to solve problems, if the method is free. Only very few students use expressions for solving problems or for illustration. The abstractness of expressions is a major handicap in traditional math courses when introducing new mathematical concepts. So the availability of different representation forms helps to differentiate and individualise the process of math teaching'. This teacher's conclusions, supported by the evidence she elicited from her own classroom experiences 
are echoed by many other teachers and lecturers who have presented outcomes of their own classroom work in ICTMT presentations and workshops over the years.

Another relevant paper by Duncan (in Bardini et al., 2009) describes the design of a more recent technological tool, which also emphasises the role of multiple representations. In his paper, Duncan presents the results of a classroom-based study that evaluated the Texas Instruments TINspire, which evolved from the previous TI-92 technology. Duncan, referring to the work of Richard Skemp (1978), poses the problem of transition from an instrumental understanding, characterised by 'rules without reasons', to a relational understanding, in which students understand what they are doing and why. In particular, he describes the study done in schools in Scotland during 2008/09 and reports the views of the teachers involved in this study. The use of multiple representations within TI-Nspire and the evidence of students' relational understanding associated with mathematical concepts is detected through the teachers' responses to his research questions. The teachers were asked in a direct way whether they perceived that the use of multiple representations facilitated by their task designs within TI-Nspire had enhanced their students' relational understanding of the mathematics involved in their lessons. The majority of teachers responded positively to this question and examples of their justification were:

- 'Pupils making connections/links between topics or single concept from different perspectives';

- 'Pupils explaining topic/lesson to others verbally - [their] discussion'; and

- 'Pupils asking/answering questions - wanting to know why'.

The evolution of technological tools has also resulted in environments that encourage the development of visualization skills in 3-D. It has always been challenging for teachers to promote the development of 3-D concepts in a traditional classroom environment using the standard chalkboard to represent 3-D objects by means of a 2-D sketch. It is generally admitted that learning 3-D geometry is strongly related to wider spatial and visual ability (Dreyfus, 1991). This has led to the creation of software that aims to develop abilities and processes in students that are closely associated with a mental scheme representing spatial information (Presmeg, 1986).

It follows that the design of some important software followed some major fields of educational theory. On the one hand, the constructivist perspective about learning, which argues that learning is personally constructed and is achieved by designing and making artefacts that are personally meaningful (Kafai \& Resnick, 1996); on the other hand, the semiotic perspective that views mathematics as a meaning-making endeavour and argues that any single sign (e.g. icon, diagram, symbol) is an incomplete representation of the object or concept, and thus multiple representations of knowledge should be encouraged during learning (Yeh \& Nason, 1994).

Several researchers offer definitions of visual and spatial ability. According to both Tarte (1990) and Linn and Petersen (1985), spatial ability is defined as the mental skills concerned with interpreting relationships visually, understanding, manipulating and reorganizing, and also as the process of representing, transforming, generating non-linguistic information.

Gutiérrez (1996) considers that the development of 3-D dynamic geometry software necessitates the following core visual abilities to be taken into account: 1. perceptual constancy, (the capability to recognise the independence among some proprieties of an object and some characteristics such as size, colour, texture, position, different orientation); 2. mental rotation, (the ability to visualise a configuration in movement); 3. perception of spatial position and spatial relationship, (the capability to relate objects, pictures or mental images to oneself or to each other); 4 . visual 
discrimination, (the ability to compare several objects, pictures, mental images to identify similarities and differences among them). Finally the access to a multitude of representations supports students to create 'correct' mental and spatial images.

These theoretical perspectives (and the associated elements of visualization) informed the design of an early 3-D geometry software environment, 3-DMath. 'The idea of 3-DMath is to develop a dynamic three dimensional geometry microworld, which enables (i) students to construct, observe and manipulate geometrical figures in 3-D space, (ii) students to focus on modeling geometric situations, and (iii) teachers to help students construct their understanding of stereometry.' (Christou, Pittalis, Mousoulides, \& Jones, in Olivero \& Sutherland, 2005).

The potential of multiple representations has also been exploited within the design of arithmetic environments. For example, the software Logotron Visual Fractions (LVF) was presented at ICTMT7 by Lehotska and Kalas (in Olivero \& Sutherland, 2005). LVF gives students the opportunity to become aware of the meaning of the different semiotic registers and provides new learning opportunities for discovering and exploring fractions and fractional relations through the dynamic dependencies and interactions of the different representations of fractions. This complex tool provides ten different visual interactive representations of fractions and the relations between them: pie, box, decimal fraction, percentage, ratio, picture, family, number line, fraction and balloon and fraction objects can be connected together to create dependencies (see Fig 3).

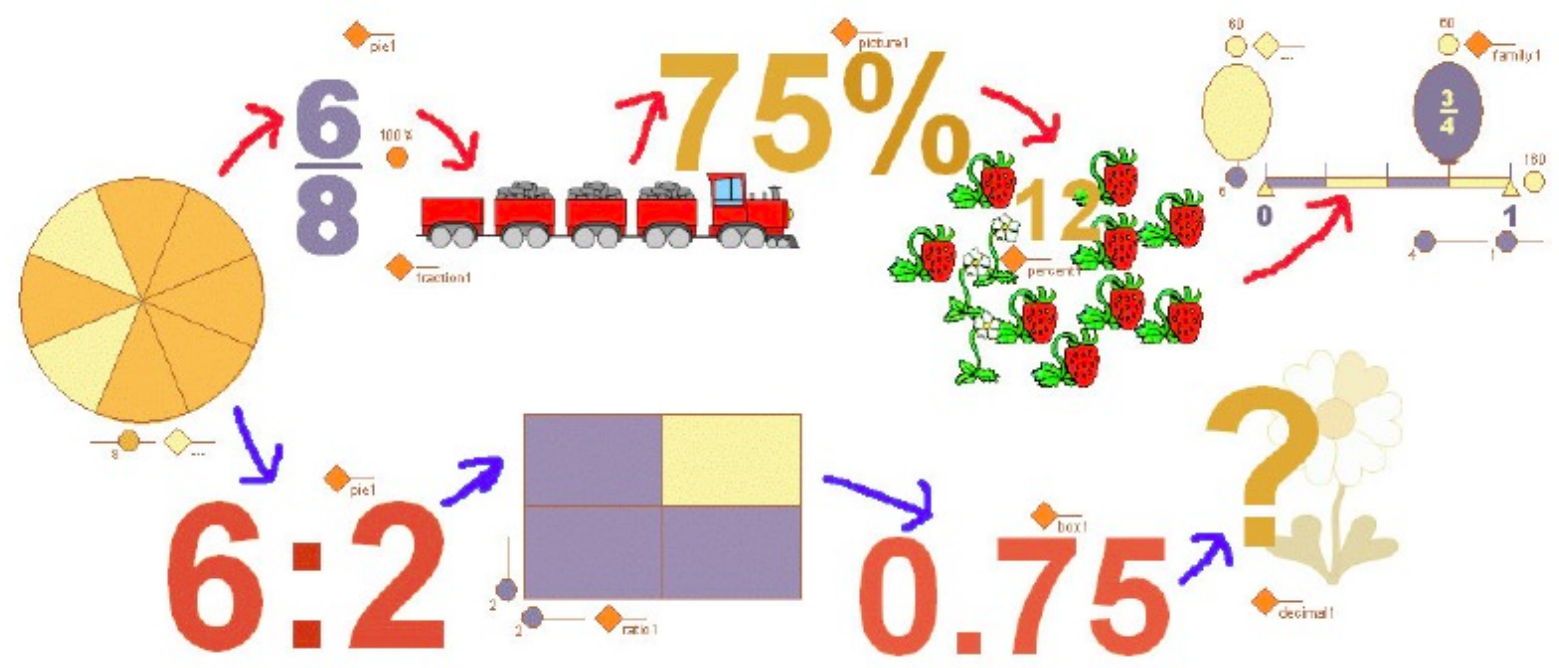

Figure 3 Two chains of dependencies of fraction objects staring with a pie with the value of $6 / 8$. (Olivero \& Sutherland, 2005, p. 110)

In this way it is possible that some objects represent values of some other objects. These dynamic dependencies and interactions give students and teachers the opportunity to observe what happens if we change the value of some object denoted by one of the representations and find the reasons why a fraction represented in one way cannot be expressed in another type of representation. For example, fractions represented by a picture 'story' such as a train with three of its four carriages filled with coal has a fixed denominator, which is why it cannot represent any value of another fraction. The relations between objects can also be more complex - more objects can depend upon the same object.

The importance of the visualization of different representations was also emphasised by Butler (in Triandafillidis \& Hatzikiriakou, 2003) in his plenary during ICTMT6. He highlighted how the exploration and use of dynamic 3-D objects (lines, vectors, planes,...) within software such as 
Autograph v.3. can help students make sense of 3-D mathematical situations where they are required to solve problems involving the intersections of planes, and the shortest distances between points. Furthermore, he underlines that for many teachers, although software offers freedom from the more limited chalkboard, it presents a serious challenge to their well-established and already effective teaching styles.

A key feature of all the tools described so far is that they offer the opportunity to improve the construction of mathematical meanings through the use of multiple representations - an innovative and unique affordance of such technology-mediated environments.

\subsubsection{Multiple representations from the perspective of the innovative design/evaluation of classroom tasks and lesson}

The value of working with multiple representations has been a consistent theme in the literature for more than two decades. However, how to integrate the use of multiple representational technology into classroom tasks and how to reorganise classroom work so as to make the most of the potential of technology to enhance learning have been recurring questions for researchers and teachers/lecturers alike.

The evidence of the ICTMT proceedings highlights the dichotomy in responding to these questions. On the one hand, several researchers underline that the complexity of mathematical structures and the multiplicity of its representations within dynamic technological environments make the mathematics difficult to learn and to understand. On the other hand, researchers have shown that the students who are more successful in mathematics are those who have been exposed to multiple representations of ideas and mathematical principles. In particular, the coexistence of the three basic components, algebra, geometry and number, in situations of teaching and learning of mathematics seems to underpin such success.

The innovation offered by the multiple representations, namely the simultaneous display of different representations of the same mathematical concept (algebraic representation, geometric and numerical) opens up the possibility of restructuring the lesson, by redefining objectives and tasks. However, this presents new challenges for teachers as they begin to create mathematical tasks that use the affordances of such software environments to produce productive activity for their students. An important contribution on this theme is given by Pierce and Stacey (in Bardini et al, 2009). They describe their research that 'reports on the use of 'lesson study' to research principles for the design of a lesson aiming to use a pedagogical opportunity at the task level: the use of multiple representations'. They identify four key principles: 'focus on the main goal for that lesson (despite the possibilities offered by having many representations available); identify different purposes for using different representations to maintain engagement; establish naming protocols for variables that are treated differently by-hand and within a machine; and reduce any sources of cognitive load that are not essential'. Furthermore the authors have elaborated the pedagogical opportunities map, which summarises the different levels (the task, the classroom, the subject of mathematics) afforded by technologies (see Fig. 4). 


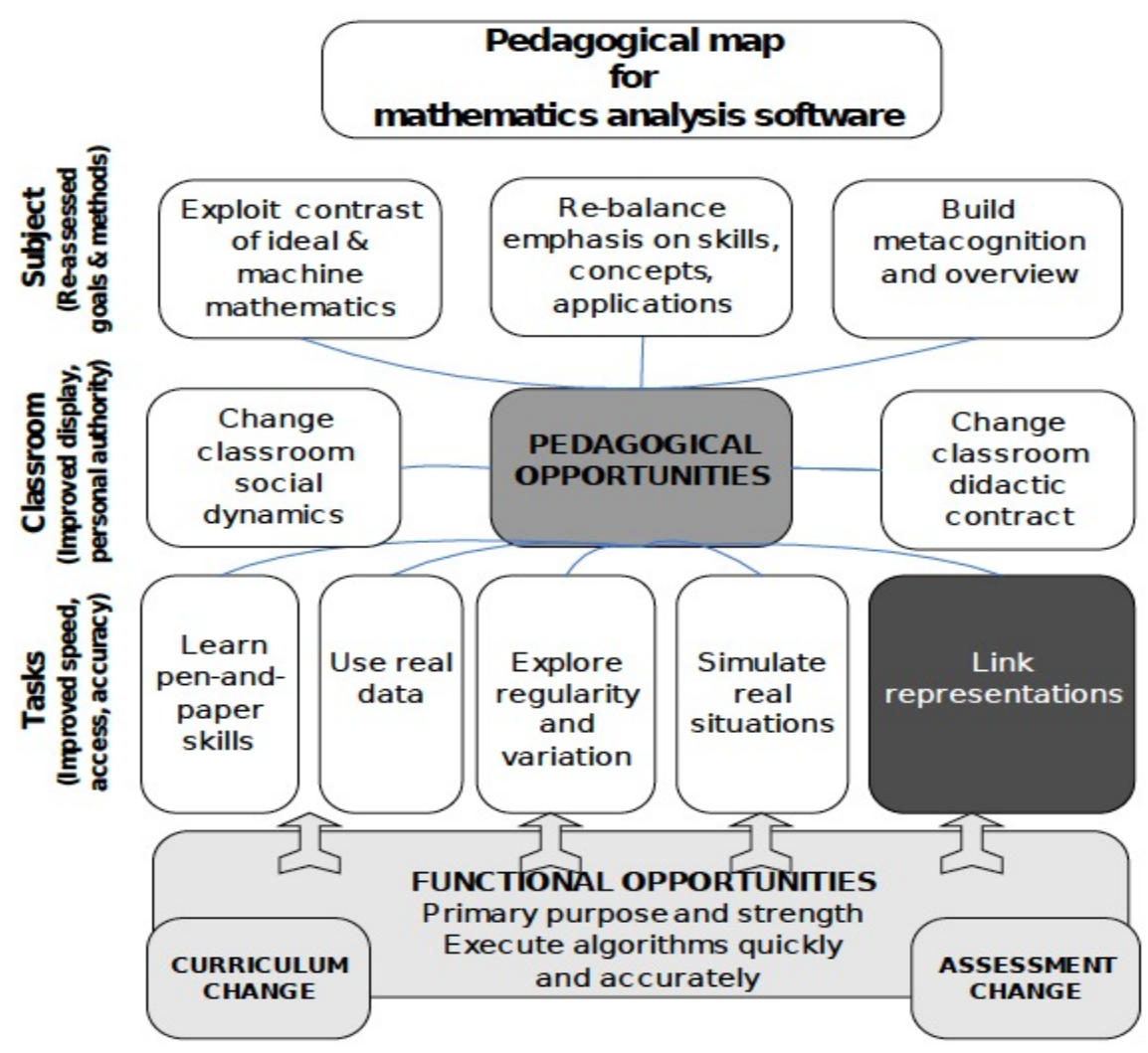

Figure 4 Pedagogical opportunities' map, emphasising linking representations at the level of classroom task design. (Pierce and Stacey, in Bardini et al, 2009)

Pierce and Stacey underline the importance of developing lessons to help teachers and students to gain advantage from access to multiple representations. Their study highlights the importance of technologies to allow students to explore problems in the new way using multiple representations. They suggest the need to focus on students' thinking on a particular area of mathematics to allow teachers to restrict the strategies supported and to plan to reduce distractions due to the technology: by establishing naming protocols and minimizing the amount of extraneous information students must deal with.

\section{Ways of interacting with mathematics through technology}

Since the first ICTMT in 1993, the ways we think about interacting with mathematical objects have evolved in line with the development of new technologies.

The word 'interact' and its derivations is prevalent within all of the ICTMT proceedings - often appearing more than 100 times in each volume - but its use is mainly as an adjective to describe all manner of innovative technological environments (see Nodelman in Bardini et al 2009). There are only a few examples where authors have probed the nature of the interaction in more depth by posing questions such as: Is it an interaction with something? Is the interaction facilitated by something? Who is doing the interaction and with what?

Lapp (in Fruanholz, 1995), in his paper on students' perception of the authority provided by the technology as they interacted with $\mathrm{TI}-82$ handheld calculators, offers a model for their interactions for aspects of their technology use. He also considers the importance of the role of the teacher's 
interactions - underlining the teacher's role in supporting the tendency for students to believe the calculator's model (or not). Lapp reported that, when faced with an apparent contradiction, the students would often refer back to the teacher's previous statements that were made during the lesson.

In her plenary talk at ICTMT7, Mariotti introduced the important theoretical point of view, semiotic mediation drawing on the work of Vygotsky to say 'it is possible to interpret the role of artefacts and their functioning as sources of meaning, from the educational point of view' (see Mariotti in Olivero \& Sutherland, 2005). She recognises Papert (1980) as the first person to acknowledge that interacting with a computer offers many different opportunities of meaningful activities and involves ways of thinking which are recognisable as typical of mathematics. However, the process of construction of mathematical meanings is not directly and simply related to the interaction with the technology. Mariotti's work contributes to the need to increase investigation on activities in computer environments in order to study the effects that such activities may have on the mathematical classroom as a whole. One of the main ideas in her paper is that the mathematical meaning related to technology becomes accessible to the learner by its use, but the construction of meanings is fostered by the guidance of the teacher. The mediating role of the teacher is essential for the interaction between the learners and the technology to be effective in terms of learning gain.

Following Texas Instruments' launch of the TI-92 handheld calculator in 1996, which incorporated a Computer Algebra System (CAS) and an interactive geometry package (based on CabriGéomètre), many ideas about the classroom use of CAS and DGS were seeded and began to take root as the ICTMT conferences were populated with papers and presentations on these themes. Teachers and researchers underlined how interactions with the different representations, which are always available on the TI-92 and its successor, the TI-Nspire, exploits the affordances of CAS and DGS, and can lead to a better understanding of mathematical concepts. For example, Duncan (see Clark-Wilson et al., 2010), who attributed the positive effect of the use of multiple representations on the development of students' relational understanding in large part to the interaction with TINspire. The interaction with the handled technology affected students' engagement, positive attitudes and perseverance in the activities, thus enhancing a genuine, deep understanding, characterised by students knowing both what to do and why. This resonates with the work of Weigand, this volume, which energizes the many studies and research involving the multiple representations of mathematical concepts to show in a powerful way how the representational capacity is constantly increased and intensified in CAS environments like GeoGebra or the later graphing calculator. But Weigand's contribution brings another side of innovation: the awareness that there is a new competence to be developed in order to take advantage of CAS in the learning of sequences, functions, or equations. And again this will mean to rethink the work with symbolic, numerical and graphical representations so as to determine the best way that a student can be supported to attain a better understanding and higher competencies in working with CAS.

More recently students are becoming increasingly familiar with touchscreen devices (such as interactive whiteboards, tablets, smartphones etc.) as they become increasingly available within and outside of classrooms. In addition, multi-touch technologies are both impacting upon and providing challenges for mathematics education as they provide a multi-modality of forms of interaction and communication that can be enriched by new ways of manipulation. Some innovative experiences conducted with the use of the new touch technologies have been presented at the more recent ICTMTs and portend to take root in the coming years.

As an example, we refer the work of Arzarello and colleagues (see their paper in Faggiano and Montone, 2013), in which they analysed and identified modes of touch screen use during the 
process of solving problems using a dynamic geometry software. Based on research by Yook (2009) and Park (2011), and distinguishing between finger action from the user and motion feedback from the interface, they observed singularities in the way students perform rotation (using one or more than one finger) and a different way of dragging (called the 'dragging to' approach). Focusing on motion feedback as a powerful strategy to improve interaction, discovering and thinking in mathematics education, Arzarello and colleagues highlighted the new challenges of interaction and learning processes in the key transition from click to touchscreen interactions.

Jackiw (in Faggiano and Montone, 2013) imagined the glass tablet screen 'as some sort of conceptual border between the Platonic realm of geometric abstraction (on the computer's side of the glass) and the tactile empire of sense experience (on the user's side)'. He questioned how multi-touch ideas could shape mathematical ideas and, alternatively, how multi-touch approaches could impact upon learners' interactions. Illustrating 'Sketchpad Explorer', he highlighted that the gesture space of a multitouch device establishes a full semiotic system, in which the conditions for mathematical structure or meaning become possible. However such innovative technologies require more work to understand how to re-craft rich software interfaces toward multi-user asynchronous uses. However, the appeal of this paper goes beyond the designers' points of view: multi-touch enables uniquely-embodied interactions with multivariate mathematics and this offer opportunities 'to both extend and rethink existing research on embodiment in Dynamic Geometry in both individual and social formations, as well as a boldly-literal new meaning for digital mathematics'.

At ICTMT11 - and in her keynote at ICTMT12 - Sinclair (see her papers in Faggiano and Montone, 2013 and in Amado and Carreira, 2015) described 'TouchCounts', an application designed for the iPad with the aim to assist young children (ages 3-8) in developing an understanding of the one-toone relationship between their fingers and numbers. As the multimodal touchscreen interface provides direct mediation through fingers and gestures, the study shows how the application seems to facilitate the establishment of number practices and the development of number sense through both the individual and collaborative finger-based interactions. The complex analysis of the way in which young children become fluent with cardinal aspects of number while using 'TouchCounts' has been developed using a new materialist theoretical lens, according to which the tool and the user mutually constitute each other through interaction (de Freitas and Sinclair, 2013). Sinclair's research, hence, represents an interesting example of another acorn which might germinate in the coming years.

The impact of these new ways of interacting and levels of connectivity are yet to be evaluated. Moreover, since 1993, the opportunities and means for the sharing of resources and ideas, and of collaborating through technological devices are maturing at great pace. Many papers, especially throughout the second half of the conference editions, deal with different aspects of the opportunities afforded by the almost ubiquitous access to information, learning materials, experts' guides, and self-assessment tools. Online courses are extremely attractive in the flexibility that they offer to learners and in recent years computer-aided learning has become a recurring addition to mathematics education. Many Virtual Learning Environments (VLEs) have been designed, implemented and experimented upon especially at the high-school and university level. High expectations seem to be placed on some of the main features of these interactive resources, such as the opportunity for students to practise and interact with mathematics anytime and anywhere and quickly receive automatic intelligent feedback on their work, or the possibility for teachers to track and review the students' progress and difficulties (see Bokhove in Milkova, 2007). 
More recently, in today's rapidly changing educational landscape, various content management systems have also been used for teachers' professional development. They seem to take advantage, in particular, of the communicating functionalities which allow students and teachers to share experiences, exchange ideas and interact with other colleagues, creating a supportive and collaborative working environment (see for instance the papers presented by the MEl team members at ICTMT10 and ICTMT11 in Joubert, Clark-Wilson and McCabe, 2011 and Faggiano and Montone, 2013, respectively).

To conclude this overview on how the many new ways of interacting with mathematics have impacted upon technology and innovation in mathematics education, a special mention should be given to the research projects that explore the affordances of e-books, which offer new kinds of flexibility, participation, and personalization. It is assumed that, as the traditional textbook will rapidly evolve from print to digital formats, the ways in which teachers and students will interact with such textbooks will also develop. In particular, the Museum Image Model of non-ordered multimodal digital textbook as presented by Michal Yerushalmy in her keynote at ICTMT11 (see her paper in Faggiano and Montone, 2013), which constitutes an interesting example of how technology could exploit research results so as to foster the development of innovative teaching and learning tools. In her view, an e-book presents opportunities for students to focus on a concept and practice related skills, making the objectives of the learning apparent, while the interaction can be guided by the tasks, by the tools, by the feedback of the interactive diagrams, and by the problems and exercises. Yerushalmy also points out that, although some teachers call for greater participation in choosing and authoring textbooks, it is unclear whether and how teachers and schools could assume an important role in designing and developing curriculum materials, and how this would change the way they use textbooks in a sustained way.

A current European Union funded project, MC-Squared is also grappling with some of the same issues. During the most recent ICTMT, members of this project team outlined its aims: to design and develop a new genre of author-able creative e-books, called c-books, which consist of pages with carefully designed interactive elements (widgets) (see the papers by Kynigos and Kalogeria and Bokhove et al. in Amado and Carreira, 2015). Several Communities of Interest (Fischer, 2001) in the different participating countries, who have diverse creative profiles, fuel the collaborative design and development of the c-books within a socio-technical environment leading to the production of creative outputs. According to the early results of the project, the c-books have the potential to foster students' creative mathematical thinking and can also function as a catalyst for teacher professional development. In particular, by engaging in design activities, teachers can develop a better understanding of the relationship between technology, pedagogy and the content being taught. This is an emerging research field which may prove to be another acorn that might take root and thrive to become an oak tree.

\section{Conclusions}

At ICTMT conferences it is not unusual to see teachers and lecturers presenting 'innovations' in their own classroom teaching that do not appear to be so innovative to the older or more experienced members of the conference community. This does suggest that despite the existence of a large body of research on technology use in mathematics education, practitioners are more likely to begin by experimenting in their own classrooms, which in turn stimulates their interest in the existing community and its research findings. The chapter proposed by Kynigos, for example, highlights the renewed importance of teachers as co-designers of digital tools and task creators, whether challenging the capacity and features of the digital media that are meant to fit the 
characteristics of his/her classroom, whether exploring more freely and boldly tasks in which students can use software tools to develop diverse approaches to mathematical questions.

Maschietto and Soury-Lavergne in this book also pose a question about the way in which digital tools seek to emulate properties and rules that define mathematical objects; this therefore means bearing in mind the importance of the feedback that digital artifacts must offer to the user. Moreover, in the case of their research, innovation is about connecting physical and digital manipulatives, and in particular exploring complementarities. The study highlights the different educational settings that teachers are able to imagine and productively organize around the use of digital tools in their classes, which reveals how innovation is essentially shaped by the teacher's action with their students.

Indeed, by participating in the ICTMT conferences, many teachers and lecturers make the first step towards becoming researchers as they engage with other participants and learn about other projects and technologies that relate to their own interests. Hence, over time it is possible to see what appears to be the same presentation - albeit from a different teacher/lecturer that uses a variety of technologies - that exemplify the presenter's personal excitement in discovering the power of dragging objects in dynamic software or the affordances of multiple representational software. What is important is that, by combining and contrasting experiences, the community works to advance both knowledge and practice in an inclusive way that takes account of different starting points.

One of the most significant technological innovations in the field, the drag mode, has now become an inherent feature in the design of most mathematical technologies that offer multirepresentational environments. Initially dragging was carried out by using the cursor keys on a computer keyboard, later using the computer mouse and now facilitated by touch screen technology; this functionality to manipulate on-screen mathematical objects has been a "gamechanger' for mathematics education research and researchers. However, repeated reports of technology use in mathematics education around the world suggest that not much has changed with respect to classroom uses of such technologies. There is still much work to be done to enable prospective and practising teachers and lecturers to experience accessible classroom tasks that enable students to interact with mathematics through the act of dragging tangible mathematical objects. Hence, each teacher and lecturer needs to become an innovator, feel the excitement of seeing his or her own students engage in purposeful, rich mathematical activity in new ways and, in turn re-evaluate their teaching approaches.

As mentioned in the introduction to this chapter, traversing through the ICTMT conference series, it is possible to identify clear tracks of innovation in the design and pedagogical uses of technological tools for the teaching and learning of mathematics at different educational levels. The characteristics that marked the evolution of educational technology stem from how deeply they have transformed the ways in which the ideas, objects and mathematical concepts are approached. The drag mode associated with the dynamic characteristics of the software is becoming the norm. The multi-representational nature of the signs and images that can be manipulated, observed, modified and connected on the screen is yet another trend that has developed as a highly relevant aspect in the teaching of mathematics. Both trends together have led to the merge of software packages. The use of increasingly portable technology has also consolidated and increased the importance given to student's independent and collaborative work in an atmosphere of problem solving, mathematical modelling and investigations, in which a key role of the teacher is guiding the student's activity with the technology. Alongside, it is noticeable that an emphasis on meaning-making and higher order thinking based on the development of 
mathematical concepts and its multiple representations has followed most of the technological innovations in mathematics education. In this regard, Sophocleous and Pitta-Pantazi (in Amado \& Carreira, 2015) present and discuss different modalities of using the opportunities offered by technology for promoting higher order thinking in mathematics. Based on research results they claim that the most successful technological environment in improving students' mathematical learning was the inquiry based technological environment.

We anticipated that our review of the ICTMT proceedings might lead us to be able to comment on innovation from the perspective of the design and evaluation of courses and assessment processes on a larger scale for participants that include school-age students, university-age students and both pre-service and in-service teachers. The ICTMT conferences have always included designers of curriculum and assessment processes who have worked in partnership with the community to develop innovation in these areas. However, whilst carrying out our review, it was noticeable how few contributions addressed the scaling of technology mediated teaching approaches. Whilst some early contributions made reference to courses in design (see Oldknow in Jaworski, 1993), there are far fewer that report evaluations of the outcomes of courses that have been established over time. Evidence from the more recent ICTMT proceedings suggest that researchers' attentions are moving towards the design and evaluation of:

- courses for upper secondary mathematics (Brockmann-Behnsen in Joubert, Clark-Wilson, \& McCabe, 2011; Weigand in Faggiano \& Montone, 2013)

- courses in undergraduate mathematics (Maclaren in Faggiano \& Montone, 2013 and Marshall, Buteau \& Muller in Faggiano \& Montone, 2013),

- courses for prospective teachers of mathematics (Abu-Elwan in Joubert, Clark-Wilson, \& McCabe, 2011; Gurevich \& Gorev in Amado \& Carreira, 2015);

- courses for practising teachers/lecturers of mathematics (Aldon et al. in Faggiano \& Montone, 2013; Clark-Wilson in Amado \& Carreira, 2015 and Thurm, Klinger, \& Barzel in Amado \& Carreira, 2015).

We predict that in the coming years, the ICTMT conference series will offer a fertile ground within which new acorns can germinate.

\title{
References
}

Adu-Gyamfi, K. (1993). External multiple representations in mathematics teaching. A thesis submitted to the Graduate Faculty of North Carolina State University in partial fulfillment of the requirements for the Degree of Master of Science.

Amado, N. \& Carreira, S. (Eds.). (2015). Proceedings of the 12th International Conference on Technology in Mathematics Teaching, Faro, Portugal: University of Algarve.

Artigue, M.. (2002). Learning mathematics in a CAS environment: The genesis of a reflection about instrumentation and the dialectics between technical and conceptual work. International Journal of Computers for Mathematical Learning, 7(3), 245-274. doi: 10.1023/A:1022103903080

\author{
Bardini, C. Fortin, P. Oldknow, A. \& Vagost D. (Eds.). (2009). Proceedings of the International \\ Conference on Technology in Mathematics Teaching 9, Metz, France.
}

Bartolini Bussi, M. G., \& Mariotti. M. A. 2008. Semiotic mediation in the mathematics classroom: Artifacts and signs after a Vygotskian perspective. In L. English, M. Bartolini Bussi, G. Jones, R. Lesh, and D. Tirosh (Eds.). Handbook of International Research in Mathematics Education, second revised edition, (pp. 746-805). Mahwah, NJ: Lawrence Erlbaum. 
Borba, M. C. \& Confrey, J. (1996). A student's construction of transformation of functions in a multiple representational environment. Educational Studies in Mathematics, 31(3), 319-397.

Borovcnik, M, \& Kautschlitsch, H (Eds.). (2002). International Conference on Technology in Mathematics Teaching 5: Plenary lectures and strands. Klagenfurt, Vienna, Austria: öbv \& hpt.

Borovcnik, M, \& Kautschlitsch, H (Eds.). (2002a). International Conference on Technology in Mathematics Teaching 5: Special groups and working groups. Klagenfurt, Vienna, Austria: öbv \& hpt.

de Freitas, E., \& Sinclair, N. (2013). New materialist ontologies in mathematics education: The body in/of mathematics. Educational Studies in Mathematics, 83(3), 453-470

diSessa, A. \& Cobb, P. (2004). Ontological Innovation and the Role of Theory in Design Experiments. Journal of the Learning Sciences, 13(1), pp. 77-103.

Dreyfus, T. (1991). On the status of visual reasoning in mathematics and mathematics education. In F. Furinghetti (Ed.), Proceedings of the 15th Conference of the International Group for the Psychology of Mathematics Education (vol 1, pp. 33-48). Genova: University of Genova.

Faggiano, E., \& Montone, A. (Eds.). (2013). Proceedings of the 11th International Conference on Technology in Mathematics Teaching, Bari, Italy: University of Bari.

Fey, J. T. (1989). Technology and mathematics education: A survey of recent developments and important problems. Educational Studies in Mathematics, 20(3), 237-272.

Fischer, G. (2001). External and Shareable Artifacts as Opportunities for Social Creativity in Communities of Interest, Proceedings of the Fifth International Conference on Computational and Cognitive Models of Creative Design, 67-89.

Fraunhalz, W. (Ed.). (1997). International Conference on Technology in Mathematics Teaching 3 Koblenz.

Guin, D., \& Trouche, L. (1999). The complex process of converting tools into mathematical instruments: The case of calculators. International Journal of Computers for Mathematical Learning, 3(3), pp. 195-227.

Gutiérrez, A. (1996). Visualization in 3-dimensional geometry: in search of a framework. In L. Puig and A. Gutierrez (Eds.) Proceedings of the 20th conference of the international group for the psychology of mathematics education (Vol. 1, pp. 3-19). Valencia: Universidad de Valencia.

Hoyles, C., \& Lagrange, J.-B. (Eds.). (2009). Mathematics Education and Technology - Rethinking the Terrain: The 17th ICMI Study. Berlin: Springer.

Hoyles, C., \& Noss, R. (2003). What can digital technologies take from and bring to research in mathematics education? In A. Bishop, M. Clements, C. Keitel, J. Kilpatrick \& F. Leung (Eds.), Second international Handbook of Mathematics Education. Dordrecht: Kluwer Academic.

Jaworski, B. (Ed.). (1993). A bridge between teaching and learning, Proceedings of the International Conference on Technology in Mathematics Teaching. University of Birmingham, UK, Sept 17-20 1993: LG Davis. 
Joubert, M., Clark-Wilson, A., \& McCabe, M. (Eds.). (2011). Enhancing Mathematics Education Through Technology. Proceedings of the International Conference on Technology in Mathematics Teaching 10. Portsmouth, UK: University of Portsmouth.

Kafai, Y. B. \& Resnick, M. (1996). Constructionism in practice: Designing, thinking, and learning in a digital world. Mahwah, NJ: Lawrence Erlbaum Associates.

Kaput, J. (1999). Representations, inscriptions, descriptions and learning: A kaleidoscope of windows. Journal of Mathematical Behavior (special issue), 17(2), 265-281.

Laborde, C. \& Sträßer, R. (2010). Place and use of new technology in the teaching of mathematics: ICMI activities in the past 25 years. ZDM - The International Journal on Mathematics Education, 42(1), 121-133.

Linn, M. C., \& Peterson, A. C. (1985). Emergence and characterization of sex differences in spatial ability: a meta-analysis. Child Development, 56, 1479-1498.

Maull, W., \& Sharp, J. (Eds.). (1999). International Conference on Technology in Mathematics Teaching 4. Plymouth, UK: University of Plymouth.

Moreno-Armella, L., Hegedus, S., \& Kaput, J. (2008). From static to dynamic mathematics: historical and representational perspectives. Educational Studies in Mathematics, 68, 99-111.

National Council of Teachers of Mathematics. (1989). Curriculum and Evaluation Standards for School Mathematics. Reston, VA: Author.

National Research Council. (1989). Everybody Counts. Washington, DC: National Academy Press.

Noss, R. \& Hoyles, C. (1996). Windows on mathematical meanings: Learning cultures and computers. Dordrecht: Kluwer Academic.

Olivero, F., \& Sutherland, R. (Eds.). (2005). Proceedings of the International Conference on Technology in Mathematics Teaching 7 (Vols. 1 and 2). Bristol, UK: Bristol University.

Ozgun-Koca, S, A. (1998). Students' use of representations in mathematics education. Paper presented at the Annual Meeting of the North American Chapter of the International Group for the Psychology of Mathematics Education (Raleigh, NC, Oct 31-Nov 2, 1998).

Papert S. (1980), Mindstorms: Children, computers, and powerful ideas. New York: Basic Books.

Park, D., Lee, J-H., \& Kim, S. (2011). Investigating the affective quality of interactivity by motion feedback in mobile touchscreen user interfaces. International Journal of Human-Computer Studies 69(12): 839-853.

Ruthven, K., \& Hennessy, S. (2002). A practitioner model for the use of computer-based tools and resources to support mathematics teaching and learning. Educational Studies in Mathematics, 49, pp. 47-88.

Schwarz, B., Dreyfus, T., Bruckheimer, M. (1990). A model of the function concept in a three-fold representation. Computers and education, 14(3), 249-262.

Scott, T. (Ed.). (1995). Informal Proceedings of the International Conference on Technology in Mathematics Teaching 2, Edinburgh: Napier University. 
Shaffer, D. \& Kaput, J. (1999). Mathematics and Virtual Culture: An Evolutionary Perspective on Technology and Mathematics Education. Educational Studies in Mathematics, 37, 97-119.

Skemp, R. (1978). Relational understanding and instrumental understanding. Arithmetic Teacher, 26, 9-15.

Tall, D. (1991). Recent Developments in the Use of Computers to Visualize and Symbolize Calculus Concepts. In L. Carl Leinbach et al. (Eds.), The Laboratory Approach to Teaching Calculus, pp. 15-25. Washington, DC: Mathematical Association of America.

Tartre, L. A. (1990). Spatial orientation skill and mathematical problem solving. Journal for Research in Mathematics Education, 21(3), 216-229.

Triandafillidis, T, \& Hatzikiriakou, K. (Eds.). (2003). Proceedings of the International Conference on Technology in Mathematics Teaching 6. Volos, Greece: University of Thessally.

Verillon, P., \& Rabardel, P. (1995). Cognition and artefacts: A contribution to the study of thought in relation to instrumented activity. European Journal of Psychology of Education, 10(1), 77-102.

Yeh, A., \& Nason, R. (2004). Towards a semiotic framework for using technology in mathematics education: the case of learning 3D geometry. Paper presented at the International Conference on Computers in Education.

Yook, H. (2009). A study on the types of interactive motions in Mobile touch interface (Doctoral dissertation). Hongik University, Korea.

Zimmermann, W. (1991). Visual Thinking in Calculus. In W. Zimmermann and S. Cunningham (Eds.), Visualization in the Teaching and Learning of Mathematics, pp. 127-137. Washington, DC: Mathematical Association of America.

\section{Appendix 1. The ICTMT conference series and proceedings}

ICTMT1 - Birmingham, 1993. Jaworski, B. (Ed.). (1993). A bridge between teaching and learning, Proceedings of the International Conference on Technology in Mathematics Teaching. University of Birmingham, UK, Sept 17-20 1993: LG Davis.

ICTMT2 - Edinburgh, 1995. Scott, T. (Ed.). (1995). Informal Proceedings of the International Conference on Technology in Mathematics Teaching 2, Edinburgh: Napier University.

ICTMT3 - Koblenz, 1997. Fraunhalz, W. (Ed.). (1997). International Conference on Technology in Mathematics Teaching 3 Koblenz.

ICTMT4 - Plymouth, 1999. Maull, W., \& Sharp, J. (Eds.). (1999). International Conference on Technology in Mathematics Teaching 4 Plymouth: University of Plymouth.

ICTMT5 - Klagenfurt, 2001 - Borovcnik, M, \& Kautschlitsch, H (Eds.). (2002). International Conference on Technology in Mathematics Teaching 5: Plenary lectures and strands. Klagenfurt, Austria Vienna: öbv \& hpt. 
and Borovcnik, M, \& Kautschlitsch, H (Eds.). (2002). International Conference on Technology in Mathematics Teaching 5: Special groups and working groups. Klagenfurt, Austria Vienna: öbv \& hpt.

ICTMT6 - Volos, 2003 -Triandafillidis, T, \& Hatzikiriakou, K. (Eds.). (2003). Proceedings of the International Conference on Technology in Mathematics Teaching 6. Volos, Greece: University of Thessally.

ICTMT7 - Bristol, 2005 - Olivero, F., \& Sutherland, R. (Eds.). (2005). Proceedings of the International Conference on Technology in Mathematics Teaching 7 (Vols. 1 and 2). Bristol, UK: Bristol University.

ICTMT8 - Hradec Králové, 2007. Milkova, E. Proceedings of the International Conference on Technology in Mathematics Teaching 8. (CD-Rom) and online at http://fim.uhk.cz/ictmt8/seznam/?nazev=\&autor=\&typ=\&v=1\&Submit=Search (abstracts only)

ICTMT9 - Metz, 2009 - Bardini, C., Fortin, P., Oldknow, A., \& Vagost D. (Eds.). (2009). Proceedings of the International Conference on Technology in Mathematics Teaching 9, Metz, France.

ICTMT10 - Portsmouth, 2011 - Joubert, M., Clark-Wilson, A., \& McCabe, M. (Eds.). (2011). Enhancing Mathematics Education Through Technology. Proceedings of the International Conference on Technology in Mathematics Teaching 10. Portsmouth, UK: University of Portsmouth.

ICTMT11 - Bari, 2013 - Faggiano, E. \& Montone, A. (Eds.). (2013). Proceedings of the 11th International Conference on Technology in Mathematics Teaching, Bari, Italy: University of Bari.

ICTMT12 - Faro, 2015 - Amado, N. \& Carreira, S. (Eds.). (2015). Proceedings of the 12th International Conference on Technology in Mathematics Teaching, Faro, Portugal: University of Algarve. 